NiASA TM-85755

NASA Technical Memorandum 85755 NASA-TM-85755 19840010257

\title{
BUCKLING OF A SUBLAMINATE IN A QUASI-ISOTROPIC COMPOSITE LAMINATE
}

K. N. Shivakumar and J, D. Whitcomb

February 1984

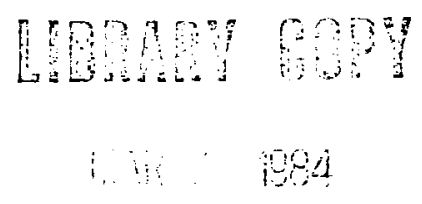

LATULEY REGEAROH U,FNIER

LESARY, MASA

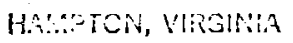

National Aeronautics and

Space Administration

Langley Research Center

Hampton, Virginia 23665 


\section{BUCKLING OF A SUBLAMINATE IN A QUASI-ISOTROPIC COMPOSITE LAMINATE \\ K. N. Shivakumar* and J. D. Whitcomb NASA Langley Research Center Hampton, Virginia 23665}

\section{SUMMARY}

Buckling of a delaminated region can cause high interlaminar stresses which, in turn lead to delamination growth. Hence, buckling strain is an Important parameter in assessing the potential for strength loss due to the delamination. The objective of this study was to predict the buckling of an elliptic delamination embedded near the surface of a thick quasi-isotropic laminate. The thickness of the delaminated ply group (the sublaminate) was assumed to be small compared to the total laminate thickness. Finite-element and Rayleigh-Ritz methods were used for the analyses. The Rayleigh-Ritz method was found to be simple, inexpensive, and accurate, except for highly anisotropic delaminated regions. Effects of delamination shape and orientation, material anisotropy, and layup on buckling strains were examined. Results showed that (1) the stress state around the delaminated region is blaxial, which may lead to buckling when the laminate ls loaded in tension, (2) buckling strains for multi-directional fiber sublaminates generally are bounded by those for the $0 \mathrm{deg}$ and $90 \mathrm{deg}$ unidirectional sublaminates, and: (3) the direction of elongation of the sublaminate that has the lowest buckling strain correlates with the delamination growth direction.

\#Research Assoclate Professor, Old Dominion University, Norfolk, VA. 


\section{INTRODUCTION}

Composite laminates often contain delaminations. Causes of delamination are many and include tool drops, bird strikes, runway debris hits, and manufacturing defects. The shape of a delamination generally resembles an ellipse $[1,2]$. Delamination can significantly reduce the compressive strength and stiffness of the laminate, primarily because the delaminated region loses flexural stiffness. Even seemingly benign delaminations sometimes initiate localized buckling, thereby creating high interlaminar stresses and extensive delamination growth. Delamination growth may lead to structural instability. Buckling and postbuckling of a near surface delamination has been addressed by several researchers both analytically and experimentally [1-7]. Analyses have been developed for strip [3,4], rectangular [1,5], circular [2] and elliptical $[6,7]$ delamination shapes. These configurations are shown in figure 1. As indicated in figure 2 the buckled region is referred to herein as the "sublaminate." In refs. 1-7, the laminate was always loaded parallel to one of the principal axes of the sublaminate. The buckling of an elliptical sublaminate of arbitrary orientation and anisotropic material properties has not been addressed.

The objective of this paper is, therefore, to investigate the buckling characteristics of a wide variety of elliptical anisotrople sublaminates delaminated from a quast-1sotropic base laminate. The thickness of the sublaminate is assumed to be small compared to the base laminate. The sublaminate is assumed to be made up of laminated fiber reinforced composite with fibers oriented at various angles relative to the loading axis. A general purpose finite-element program, STAGS [8], was employed to calculate the buckling strain of typical sublaminate configurations. Also, a simple energy method, based on a Rayleigh-Ritz $(R-R)$ formulation, was developed for the 
parametric study. The $R-R$ analysis was evaluated by comparing it to the finite element analysis. In this paper results are presented for variety of four ply sublaminates.

\section{NOMENCLATURE}

a

$$
\left.\begin{array}{l}
A_{11}, A_{12}, A_{16} \\
A_{22}, A_{26}, A_{66}
\end{array}\right\}
$$

b

$\mathrm{C}_{0}$

$\mathrm{c}_{1}, \mathrm{c}_{2}$

$\left.\begin{array}{l}D_{11}, D_{12}, D_{16} \\ D_{22}, D_{26}, D_{66}\end{array}\right\}$

E

G

h

[K]

$\left[\mathrm{K}_{1}\right],\left[\mathrm{K}_{2}\right],\left[\mathrm{K}_{3}\right]$

$\left[\mathrm{K}_{\mathrm{g}}\right]$

$\mathrm{N}$

$N_{x^{\prime}}, N_{y^{\prime}}, N_{x^{\prime}} y^{\prime}$

U

$\mathbf{u}$

V

$\mathbf{v}$

w

$x-y-z$

$x^{\prime}-y^{\prime}-z^{\prime}$ half-length of an elliptic sublaminate, m

inplane stiffness coefficients of the sublaminate, $\mathrm{N} / \mathrm{m}$ half-width of an elliptic sublaminate, m generalized displacement, m generalized displacements, $\mathrm{m}^{-1}$

flexural stiffness coefficlents of the sublaminate, $N / m$ Young's modulus, MPa

shear modulus, $\mathrm{MPa}$

thickness of the sublaminate, m bending stiffness matrix of the sublaminate

bending stiffness coefficient matrices

geometric stiffness matrix of the sublaminate

number of laminae in the sublaminate

sublaminate stress resultants, N/m

strain energy of the deformed sublaminate, $J$

displacement in the $x^{\prime}$-direction, m

potential energy due to loading, $J$

displacement in $y^{\prime}$-direction, m

transverse (z) displacement, m

base laminate Carteslan coordinate system

sublaminate Cartesian coordinate system 
$\alpha$

$\varepsilon$

$\varepsilon_{\mathrm{x}}$ $\varepsilon_{\mathrm{x} 1}$

$\theta$

$v_{\text {lam }}$

II

Subscripts

1

$\ell, t$

$x, y$

$x^{\prime}, y^{\prime}$

Definitions

Buckling strain: base laminate strain at which the sublaminate buckles

Delamination: a separation between plies of a laminate

Sublaminate: a set of intact plies separated from a thick laminate by a

fiber angle of a lamina in a sublaminate, degree

Inplane strain

buckling strain

one-term buckling strain

angle between $x$ and $x^{\prime}$ axes

Poisson's ratio of the laminate

total potential energy of the sublaminate, $J$

ply number

along or transverse to fiber direction

$x$ or $y$ direction

$x^{\prime}$ or $y^{\prime}$ direction

\section{Base laminate: group of plies below the sublaminate} delamination

\section{DESCRIPTION OF THE PROBLEM}

Figures $2(a)$ and $2(b)$ show plan and sectional views of a quasi-isotropic composite laminate with a single delamination. As shown, the $x-y-z$ coordinate system is orlented such that the $x$-axis is along the laminate loading direction. The laminate is loaded to a strain $\varepsilon_{x}$ in the $x$-direction. (A positive value of $\varepsilon_{x}$ refers to tensile strain.) The associated strain in the y-direction is $-\nu_{\text {lam }} \varepsilon_{x}$, where $\nu_{\text {lam }}$ is the base laminate Poisson's ratio. 
The plan view of an assumed elliptic delamination is shown in figure $2(a)$. The set of intact laminae delaminated from the laminate is referred to as the "sublaminate;" the remaining laminate is referred to as the base laminate. The principal axes of the sublaminate are $x^{\prime}$ and $y^{\prime}$; the corresponding semiaxes lengths are $a$ and $b$. The angle between the axes $x^{\prime}$ and $x$ is $\theta$, which is referred to herein as the sublaminate angle. The sublaminate is assumed to be made up of $N$ laminae; $\alpha$ is the fiber angle of a lamina measured relative to the $x$-axis (see figure $2(a)$ ). The sublaminate thickness is $h$ and is assumed to be small compared to the base laminate thickness. Therefore, inplane displacements around the sublaminate boundary can be calculated from the base laminate inplane deformations. Furthermore, the sublaminate lateral dimensions ( $a$ and $b$ ) are assumed to be relatively large compared to $h$, and, hence, thin plate linear buckling theory is assumed to be valid. The buckled shape of a sublaminate is shown in figure $2(b)$. The transverse deflection $w$ is measured from the sublaminate mid-plane. The transverse displacement and slopes are zero along the sublaminate boundary. The present analyses assume that the sublaminate buckles outward from the base laminate, as shown in figure 2(b). Furthermore, effects of higher modes and inward buckling of the sublaminate are neglected. The in-plane forces acting on the sublaminate due to the laminate strain $\varepsilon_{x}$ were calculated from lamination theory [9] and are shown, schematically, in figure 2(c). Even though the base laminate is under uniaxial stress, the local stress distribution in the sublaminate is generally biaxial due to either a difference in the Poisson's ratio of the sublaminate and the base laminate, or to sublaminate material anisotropy. Note that the buckling initiation problem is reduced to that of an idealized elliptic sublaminate subjected to a set of inplane boundary forces. 
ANALYSIS

Two analyses were used to calculate the buckling strains of the sublaminate: Finite-element $(F-E)$ and Rayleigh-Ritz $(R-R)$. Both analyses were based on the adjacent equilibrium buckling criterion (see for example ref. 10). The finite-element analysis was performed using the sTAGS [8] computer code. The F-E analysis, although versatile and accurate, is a relatively expensive computer analysis, especially for eigen value problems involving a large number of degrees of freedom. Therefore, an additional simplified analysis based on the Rayleigh-Ritz technique was developed. The $R-R$ analysis is known to give accurate results for specially orthotropic sublaminates [11]. The term special orthotropy refers to an orthotroplc sublaminate, one of whose principal axes is aligned with the applied load direction. In this study, the $R-R$ method was used for both specially orthotropic and anisotropic sublaminates. The accuracy of the analysis was assessed using the STAGS finiteelement analysis. The two analyses are described in the following sections.

The Finite Element Analysis

The general purpose finite element program STAGS [8] was used in the present study. An eighteen degree-of-freedom triangular plate element having three displacement and two rotational degrees-of-freedom (d.o.f.) at the corner nodes and one rotational d.o.f. at each mid-side node was employed for the analysis. Specially orthotropic cases were analyzed using only a quarter of the sublaminate whereas generally anisotropic cases were analyzed using the full sublaminate idealization. The two idealizations are shown in figure 3 . The following boundary conditions were used in the analyses: (1) Quarterplate, $v=w_{y^{\prime}}=0$ along $\mathrm{OA}_{,} \mathrm{u}=\mathrm{w}_{\mathrm{x}^{\prime}} \mathrm{x}^{\prime}=0$ along $\mathrm{OB}$, and $\mathrm{w}^{\prime}=\mathrm{w}_{\mathrm{x}^{\prime}}=\mathrm{w}_{\mathrm{y}^{\prime}}=0$ along $A B ;$ (2) Full plate, $w=w_{, x^{\prime}}=w_{, y^{\prime}}=0$ along the entire outer boundary. The variables $u, v$, and $w$ are the displacements in the $x^{\prime}, y^{\prime}$ and 
$z$ directions, respectively, and the comma indicates partial differentiation $\left(\right.$ e.g., $\left.w_{x^{\prime}}=\frac{\partial w}{\partial x^{\prime}}\right)$. For a specified base laminate axial strain $\varepsilon_{x^{\prime}}$ the sublaminate boundary forces (see fig. $2(c)$ ) were input as initial stresses in the finite element analysis.

Convergence was studied to determine the degree of mesh refinement required for specially orthotropic and generally anisotropic sublaminates. A quarter plate sublaminate of $8 \times 12$ (1.e., elght equal parts along the $x^{\prime}-a x i s$ and twelve equal parts along the circumference) mesh is shown in figure $3(a)$. Calculated buckling strains using $4 \times 6,8 \times 12$, and $16 \times 24$ meshes for a unidirectional 0 deg sublaminate indicate that the buckling strain for $8 \times 12$ mesh differed by less than $1 \%$ from that for $16 \times 24$ mesh. Thus, the $8 \times 12$ mesh was employed for all isotropic and specially orthotropic sublaminates. A similar convergence study for a unidirectional with $\alpha=45 \mathrm{deg}$ sublaminate (which is anisotropic) indicated that the $8 \times 32$ mesh (see fig. 3(b)) predicts buckling strain within $1 \%$ from that of the more refined mesh. Thus, $8 \times 32$ mesh was employed for all anisotropic cases.

\section{The Raleigh-Ritz Analysis}

Even though the finite element method is versatile it is expensive, especially for eigenvalue analysis of problems with a large number of degrees of freedom. Therefore a simple Raleigh-Ritz analysis, based on the Trefftz criterion [10], is presented to calculate buckling strains of elliptic sublamInates. The procedure consists of three steps: (1) selection of a kinematically admissible transverse displacement function; (2) calculation of the total potentlal energy; and then (3) application of the Trefftz criterion [10] to yleld eigenvalue equations. The elgenvalue equations were solved numerically for different sublaminate configurations and stacking sequences. The governing equations are derived below. 
Strain energy of sublaminate.- The strain energy $U$ of the buckled sublaminate is [9]

$$
\begin{aligned}
U= & \frac{1}{2} \int_{-a}^{a} \int_{-b}^{b} D_{11}\left(\frac{\partial^{2} w}{\partial x^{\prime 2}}\right)^{2}+D_{22}\left(\frac{\partial^{2} w}{\partial y^{\prime}}\right)^{2} \\
& +2 D_{12}\left(\frac{\partial^{2} w}{\partial x^{\prime 2}}\right)\left(\frac{\partial^{2} w}{\partial y^{\prime 2}}\right)+4 D_{66}\left(\frac{\partial^{2} w}{\partial x^{\prime} \partial y^{\prime}}\right)^{2} \\
& \left.+\left[4 D_{16}\left(\frac{\partial^{2} w}{\partial x^{\prime 2}}\right)\left(\frac{\partial^{2} w}{\partial x^{\prime} \partial y^{\prime}}\right)+D_{26}\left(\frac{\partial^{2} w}{\partial y^{\prime 2}}\right)\left(\frac{\partial^{2} w}{\partial x^{\prime} \partial y^{\prime}}\right)\right]\right\} d x^{\prime} d y^{\prime}
\end{aligned}
$$

where the $D^{\prime} s$ are the flexural stiffness constants for an anisotropic sublaminate [9]. The transverse deflection $w$ of the deformed sublaminate is assumed to given by

$$
w=\left[1-\left(\frac{x^{\prime}}{a}\right)^{2}-\left(\frac{y^{\prime}}{b}\right)^{2}\right]^{2}\left\{c_{0}+c_{1} x^{\prime 2}+c_{2} y^{\prime 2}\right\}
$$

where $C_{0}, C_{1}$, and $C_{2}$ are generalized displacements. The $w$ function satisfies zero deflection and slope conditions along the boundary of the sublaminate. Substituting eqn. (2) in eqn. (1) and performing the necessary differentiation and integration, eqn. (1) becomes

$$
\mathrm{U}=\{\mathrm{C}\}^{\mathrm{T}}[\mathrm{K}]\{\mathrm{C}\}
$$

where $\{C\}^{T}=\left\{C_{0}, C_{1}, C_{2}\right\}$ and the stiffness matrix $K$ is

$$
[K]=D_{11}\left[K_{1}\right]+D_{22}\left[K_{2}\right]+2\left[K_{3}\right]\left(D_{12}+2 D_{66}\right)
$$

The matrices $\mathrm{K}_{1}, \mathrm{~K}_{2}$ and $\mathrm{K}_{3}$ are defined as follows: 


$$
\begin{aligned}
& {\left[\mathrm{K}_{1}\right]=\frac{\pi b}{\mathrm{a}^{3}}\left[\begin{array}{ccc}
4 & 0.5 & 0.5 \\
& 1.35 & 0.05 \\
\text { Symmetric } & 0.15
\end{array}\right]} \\
& {\left[\mathrm{K}_{2}\right]=\frac{\pi \mathrm{a}}{\mathrm{b}^{3}}\left[\begin{array}{ccc}
4 & 0.5 & 0.5 \\
0.15 & 0.05 \\
\text { Symmetric } & 1.35
\end{array}\right]} \\
& {\left[\mathrm{K}_{3}\right]=\frac{\pi}{6 \mathrm{ab}}\left[\begin{array}{cc}
8 & 1 \\
1 & 0.5 \\
\text { Symmetric } & 1.1
\end{array}\right]}
\end{aligned}
$$

Since the assumed $w$ deflection function is symmetric, coefficients of $D_{16}$ and $\mathrm{D}_{26}$ vanish in the process of differentiation and integration; hence, these terms do not appear in eqn. (4).

Potential energy of applied loads.- The potential energy $V$ of the stress resultants is given by [9]

$$
V=\frac{1}{2} \int_{-a}^{a} \int_{-b}^{b}\left[N_{x^{\prime}}\left(w^{\prime} x^{\prime}\right)^{2}+N_{y^{\prime}}\left(w_{y^{\prime}}\right)^{2}+2 N_{x^{\prime} y^{\prime}}\left(w, x^{\prime} w_{y^{\prime}}\right)\right] d x^{\prime} d y^{\prime}
$$

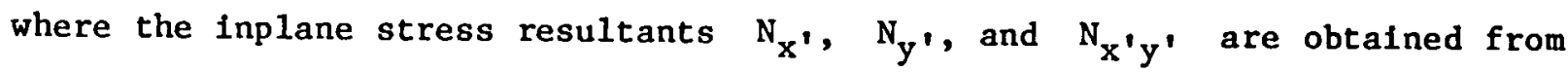
lamination theory [9] as follows

$$
\begin{aligned}
& N_{x^{\prime}}=A_{11} \varepsilon_{x^{\prime}}+A_{12} \varepsilon_{y^{\prime}}+A_{1} \varepsilon_{x^{\prime} y^{\prime}} \\
& N_{y^{\prime}}=A_{12} \varepsilon_{x^{\prime}}+A_{22} \varepsilon_{y^{\prime}}+A_{26} \varepsilon_{x^{\prime} y^{\prime}} \\
& N_{x^{\prime} y^{\prime}}=A_{16} \varepsilon_{x^{\prime}}+A_{26} \varepsilon_{y^{\prime}}+A_{66} \varepsilon_{x^{\prime} y^{\prime}}
\end{aligned}
$$

The sublaminate strains $\varepsilon_{x^{\prime}}, \varepsilon_{y^{\prime}}$ and $\varepsilon_{x^{\prime} y^{\prime}}$ are expressed in terms of the base laminate strain $\varepsilon_{x}$, the Poisson's ratio $\nu_{1 a m}$, and the sublaminate angle $\theta$ as follows 


$$
\begin{aligned}
& \varepsilon_{x^{\prime}}=\left(\cos ^{2} \theta-v_{1 a m} \sin ^{2} \theta\right) \varepsilon_{x} \\
& \varepsilon_{y^{\prime}}=\left(\sin ^{2} \theta-v_{1 a m} \cos ^{2} \theta\right) \varepsilon_{x} \\
& \varepsilon_{x^{\prime} y^{\prime}}=-\left(1+v_{1 a m}\right) \sin 2 \theta \varepsilon_{x}
\end{aligned}
$$

Substituting the expression for $w$ from eqn. (2) into eqn. (5) and performing the necessary differentiation and integration, eqn. (5) simplifies to

$$
V=\{C\}^{T}\left[K_{g}\right]\{C\} \varepsilon_{x}
$$

The geometric stiffness matrix $\mathrm{K}_{\mathrm{g}}$ is symmetric. The elements in the upper half of the $\left[\mathrm{K}_{\mathrm{g}}\right]$ are defined as follows

$$
\begin{aligned}
& K_{g_{11}}=\frac{\pi}{3}\left(\frac{b}{a}\right)\left[\left(A_{11}-v_{1 a m} A_{12}\right)+\left(\frac{a}{b}\right)^{2}\left(A_{12}-v_{1 a m} A_{22}\right)\right] \\
& K_{g_{12}}=\frac{\pi}{30 a b}\left[A_{12}-v_{1 a m} A_{22}\right] \\
& K_{g_{13}}=\frac{\pi}{30 a b}\left[A_{11}-v_{1 a m} A_{12}\right] \\
& K_{g_{22}}=\frac{\pi}{120}\left(\frac{b}{a}\right)\left[3\left(A_{11}-v_{1 a m} A_{12}\right)+\left(\frac{a}{b}\right)^{2}\left(A_{12}-v_{1 a m} A_{22}\right)\right] \\
& K_{g_{23}}=0 \\
& K_{g_{33}}=\frac{\pi}{120}\left(\frac{a}{b}\right)\left[\left(\frac{b}{a}\right)^{2}\left(A_{11}-v_{1 a m} A_{12}\right)+3\left(A_{12}-v_{1 a m} A_{22}\right)\right]
\end{aligned}
$$

The shear-extension coupling terms $A_{16}$ and $A_{26}$ do not appear in eqn. (9) because the $w$ displacement function was symmetric. 
Buckling equation.- The total potential energy, $\Pi$, of the sublaminate is sum of the strain energy $U$ and the potential energy $V$.

$$
\mathrm{I}=\mathrm{U}+\mathrm{V}
$$

Applying the Trefftz criterion $[10], i . e .,\left|\frac{\partial^{2} \pi}{\partial C_{i}{ }^{2}}\right|=0,1=0,1,2$ yields the eigenvalue equation.

$$
\left|[K]+\varepsilon_{x}\left[K_{g}\right]\right|=0
$$

The solution of eqn. (11) results in three elgenvalues which correspond to the three buckling modes. The lowest absolute eigenvalue corresponds to the first buckling mode and is referred to as the buckling strain $\varepsilon_{x_{c}}$ of the sublaminate.

To illustrate how the material anisotropy and the sublaminate size influence the buckling strain, eqn. (11) is simplified to that for a one term solution. This corresponds to an assumed deflection function $\mathrm{w}=\left[1-\left(\frac{\mathrm{x}^{\prime}}{\mathrm{a}}\right)^{2}-\left(\frac{\mathrm{y}^{\prime}}{\mathrm{b}}\right)^{2}\right]^{2} \mathrm{c}_{0}$. Therefore, substituting $\mathrm{c}_{1}=\mathrm{c}_{2}=0$ in eqns. (3) and (5) and applying the Treffetz criterion yields

$$
\varepsilon_{x_{c 1}}=-\frac{12}{b^{2}} \frac{\left[\left(\frac{b}{a}\right)^{2} D_{11}+\left(\frac{a}{b}\right)^{2} D_{22}+\frac{2}{3}\left(D_{12}+2 D_{66}\right)\right]}{A_{11}+\left\{\left(\frac{a}{b}\right)^{2}-v_{1 a m}\right\} A_{12}-v_{1 a m}\left(\frac{a}{b}\right)^{2} A_{22}}
$$

where $\varepsilon_{\mathrm{x}_{\mathrm{cl}}}$ is the one term buckling strain. Equation (12) shows that the sign of $\varepsilon_{x_{c l}}$ depends only on the sign of the denominator, which is a function of the size and the in-plane stiffness coefficients of the sublaminate, and the laminate Poisson's ratio $\nu_{1 a m}$. If the denominator is negative, the sign of the buckling strain $\varepsilon_{x_{c 1}}$ is positive. This indicates that the sublaminate may buckle when the base laminate is loaded in tension. This 
phenomenon may appear unusual, but it is caused by the mismatch of Poisson's ratio between sublaminate and the base laminate. For example, if a quasiisotropic base laminate having a Poisson's ratio of 0.3 is stretched to a strain $\varepsilon_{x}$, it contracts laterally (in the $y$-direction) by $-0.3 \varepsilon_{x}$. A delaminated $90 \mathrm{deg}$ fiber sublaminate, which has a very. low Polsson's ratio (say 0.03 ), contracts only by $-0.03 \varepsilon_{x}$. The unequal contraction in the $y$-direction introduces a net compressive strain of $-0.27 \varepsilon_{x}$ on the sublaminate. Such compressive strain acting in the fiber direction of the $90 \mathrm{deg}$ fiber sublaminate may cause local buckling, even though the base laminate is loaded in tension. Equation (12) also shows that the sign of the denominator depends on the aspect ratio $\mathrm{b} / \mathrm{a}$ of the sublaminate. The effect of sublaminate material properties and aspect ratio on buckling is discussed further in the next section.

\section{RESULTS AND DISCUSSION}

Buckling strains of a surface sublaminate in a quasi-isotropic graphitel epoxy composite laminate were calculated using the finite-element (F-E) and the Rayleigh-Ritz $(R-R)$ analyses. The $R-R$ analysis was compared with $F-E$ analysis for typical cases. Buckling strains for four-ply sublaminates were calculated for various sublaminate sizes, orientations, fiber angles and layups. The plot of buckling strains versus sublaminate properties is referred to as the buckling curve. Material properties used in the analyses are given in Table 1.

Isotroplc sublaminate.- Figure 4 compares buckling strains calculated from the $F-E$ and $R-R$ analyses for an isotropic (material properties for aluminum were used), elliptical sublaminate for different values of $b$. The F-E results are shown by symbols and the $R-R$ results by a solid line. The two analyses agree very well. The compression buckling strain decreases in 
magnitude monotonically as the sublaminate width, b, increases and asymptotically approaches the strip solution ( $b \gg$ a).

Specially orthotropic sublaminates.- Figure 5 shows buckling curves for $0 \mathrm{deg}$ and $90 \mathrm{deg}$ unidirectional sublaminates. The 0 deg unidirectional sublaminate buckles only by compressive remote strain (as was the case for the isotropic sublaminate). The buckling strain asymptotically approaches a constant value with Increased b. The 90 deg unidirectional sublaminate, as already explained with reference to eqn. (12), can buckle under tension and compression remote strain. The buckling caused by tension remote strain is referred to herein as tension buckling and buckling due to compression remote strain is referred to as compression buckling. Results in figure 5 and an examination of buckling modes (not reported here) Indicate that the first mode of buckling for a $90 \mathrm{deg}$ unidirectional sublaminate only occurred for remote tension for $b<25 \mathrm{~mm}$ and only for remote compression for $b>64 \mathrm{~mm}$. Both compression and tension buckling of a sublaminate are possible for values of b between 25 and $64 \mathrm{~mm}$. Higher modes of buckling involve both positive and negative lateral displacements. The base laminate would interfere with these negative lateral displacements of the sublaminate. To account for this interference requires the solution of a nonlinear contact problem, which is beyond the scope of the present paper. Hence, higher mode buckling strains are not reported here.

The tension buckling strain for $b=12.5 \mathrm{~mm}$ is 0.0051 , which is higher than the splitting threshold for unidirectional graphite/epoxy laminate (transverse tenslle strength $=40 \mathrm{MPa}$, ref. 12). Therefore, the $90 \mathrm{deg}$ unidirectional sublaminate for $b<19$ may split before buckling. The splitting would reduce the buckling straln. The two analyses agree very well with each other for both sublaminates. 
Anisotropic sublaminates.- The lower half of figure 6 shows the effect of fiber angle $\alpha$ on buckling strain for unidirectional fiber, circular sublaminates. The compression buckling strain increases with increasing fiber angle. But at fiber angles of $75 \mathrm{deg}<\alpha<90 \mathrm{deg}$, the sublaminate buckles also under tensile laminate strain. The $F-E$ and $R-R$ analyses agree well for $0<\alpha<55 \mathrm{deg}$ and $80 \mathrm{deg}<\alpha<90 \mathrm{deg}$. For fiber angles $55 \mathrm{deg}<\alpha<80 \mathrm{deg}$, the $R-R$ analysis overestimates the buckling strain, because the bendingtwisting $\left(D_{16}\right.$ and $\left.D_{26}\right)$ and shear-extension $\left(A_{16}\right.$ and $A_{26}$ ) coupling terms were not included. However, for other fiber angles the influence of these terms is less significant and hence the $R-R$ results agree with the $F-E$ results. The upper portion of figure 6 also shows the effect of fiber angle on major Polsson's ratio $\left(\nu_{x^{\prime}} y^{\prime}\right)$ of the sublaminate. The Poisson's ratio of the base laminate is also shown in figure 6 for reference. Comparison of the buckling curve and Polsson's ratio curves indicate (1) the buckling strain of the sublaminate is compressive and is relatively small for sublaminate Polsson's ratio greater than the base laminate; (2) buckling strain increases in magnitude as the sublaminate Polsson's ratio decreases and falls below the laminate value; and (3) the first mode of buckling changes from compression to tensile buckling for very low sublaminate Poisson's ratio.

Figure 7 shows the effect of fiber angle on the buckling strain for three unidirectional elliptical sublaminates with different aspect ratios. The length " $a$ " was held constant $(a=25.4 \mathrm{~mm})$; the widths $b=a / 2, a$ and $2 \mathrm{a}$. Results for the circular sublaminate in figure 6 are repeated here. Buckling strains for $b / a=0.5$ were compressive for $\alpha<60 \mathrm{deg}$ and became tensile for $\alpha$ close to $90 \mathrm{deg}$. In contrast, buckling strains of $b=2 a$ sublaminate remalned compressive for all fiber angles. Buckling strain magnitude decreased monotonically with increase in sublaminate width, b. 
Oblique sublaminate.- The effect of fiber angle on the buckling of oblique sublaminates is shown in figure 8. Buckling curves are shown for unidirectional sublaminate angles $\theta=0,15,30,45,60$, and 90 degrees. The sublaminate size is $a=25.4, b=50.8$, and $h=0.51 \mathrm{~mm}$. Figure 8 shows that for fiber angles $0<\alpha<38 \mathrm{deg}$, buckling strain decreases slightly with increasing sublaminate angle. The trend is reversed for $\alpha>38 \mathrm{deg}$. For $\theta=0$ and 15 deg the buckling strain is compressive for all fiber angles; whereas for $30 \mathrm{deg}<\theta<90 \mathrm{deg}$ the buckling strain changes to tensile for $\alpha>70 \mathrm{deg}$. Figure 9 shows the effect of sublaminate angle on buckling strain for $[0]_{4},[90]_{4},[0 / 90]_{s},[ \pm 45]_{s}$, and $[0 / \pm 45 / 90]$ sublaminates. The figure shows that the buckling strains for $[0 / 90]_{S},[ \pm 45]_{S}$, and $[0 / \pm 45 / 90]$ sublaminates are generally bounded by those of the $[0]_{4}$ and $[90]_{4}$ sublaminates. The buckling strain for a $[0]_{4}$ sublaminate decreases with increasing sublaminate angle $\theta$; for a $[90]_{4}$ sublaminate the buckling strain increases. Furthermore, buckling strains of $[0]_{4},[0 / 90]_{S},[ \pm 45]_{S}$, and $[0 / \pm 45 / 90]$ sublaminates are quite small (less thän 0.0015) and compressive for all sublaminate angles. Criterion for delamination growth direction.- For the configuration being studied, there are no interlaminar stresses around the delamination boundary until the delaminated region buckles. Whether the delamination grows after buckling depends on many parameters, including sublaminate size, sublaminate In-plane and flexural stiffness, and the interlaminar fracture toughness of the material. If we assume the delamination w11l grow, the question remains: "What direction will the delamination grow?" The possibility that the direction of initial growth for a circular delamination could be predicted based on changes in the buckling strain was investigated. The delamination was assumed to be initially circular $(a=b=25.4 \mathrm{~mm})$. Then, it was assumed to grow in the load $(x)$ direction by $50 \%(a=38.1$, and $b=25.4 \mathrm{~mm})$ or transverse to the 
load direction by $50 \%(a=25.4$, and $b=38.1 \mathrm{~mm})$. Buckling strains for the three configurations were calculated for $[0]_{4},[0 / 90]_{s},[ \pm 45]_{s}$, and $[0 / \pm 45 / 90]$ sublaminates. Figure 10 shows the calculated results and the experimentally observed growth directions $[1,2,13]$. The $[0]_{4}$ sublaminate buckling strain is lowest when it is elongated in the load direction. In tests reported in reference 13 the delamination also grew in the load direction, accompanfed with splitting. On the other hand the buckling stralns for $[0 / 90]_{S},[ \pm 45]_{S}$, and $[0 / \pm 45 / 90]$ sublaminates are lower when the delamination is elongated perpendicular to the load direction, which is also the experimentally observed growth direction [1,2]. Apparently, the direction of elongation of the sublaminate that has the lowest buckling strain will be the initial direction of growth of a circular delamination. More tests and analyses are needed to verify this interpretation.

\section{CONCLUSIONS}

Finite-element $(F-E)$ and Rayleigh-Ritz $(R-R)$ analyses were used to predict the buckling strain of a localized delamfnated region in a quasiisotropic laminate. The $R-R$ analysis, developed using the Trefftz criterion, is simple and inexpensive compared to the F-E analysis. The accuracy of the $R-R$ analysis was evaluated by comparing with the $F-E$ analysis. Calculated buckling strains from the $R-R$ analysis agreed with the $F-E$ results except for highly anisotropic sublaminates; the neglect of the bending-twisting $\left(D_{16}\right.$ and $\mathrm{D}_{26}$ ) and the shear-extension $\left(\mathrm{A}_{16}\right.$ and $\mathrm{A}_{26}$ ) coupling terms caused significant errors for these sublaminates. However, the region where the $R-R$ method is invalid was small. A parametric study was performed for a four ply sublaminate to assess the influence of materfal anfsotropy, and sublaminate angle shape and layup on buckling strains. The laminate was assumed to be made up of graphite/epoxy composite. This study led to the following conclusions: 
(1) Even though the base laminate is in a uniaxial stress state, the sublaminate is generally in a blaxial stress state efther due to a mismatch of Poisson's ratio or to material anisotropy.

(2) The biaxial stress states in some unidirectional composite sublaminates cause tensile buckling when the sublaminate is elongated in the load direction and fibers are nearly perpendicular to load direction.

(3) Compressive buckling strain for unidirectional sublaminates increases with the increase in the angle between the load and the fiber directions.

(4) The buckling strains for $[0 / 90]_{s},[ \pm 45]_{S}$, and $[0 / \pm 45 / 90]$ sublaminates are generally bounded by those for $[0]_{4}$ and $[90]_{4}$ sublaminates.

(5) The direction of elongation of the sublaminate that has the lowest buckling straln correlates with the intilal growth direction of a circular delamination.

\section{REFERENCES}

1. Konishi, D. Y., and Johnson, W. R., "Fatigue Effects on Delaminations and Strength Degradations in Graphite/Epoxy Laminates," Composite materials: Testing and design, Proceedings of the Fifth Conference, New Orleans, Louistana, March 20-22, 1978. (A80-21126 07-24) Philadelphia, Pennsylvania, American Society for Testing and Materials, 1979, pp. 597-619.

2. Webster, J. D., "Flow Criticality of Circular Disbond Defects in Composite Laminates," NASA CR-164830, March 1981.

3. Whitcomb, J. D., "Finite Element Analysis of Instability Related Delamination Growth," NASA TM 81964, March 1981.

4. Whitcomb, J. D., "Strain Energy Release Rate Analysis of Cyclic Delamination Growth in Compressively Loaded Laminates," NASA TM 84598, January 1983. 
5. Ashizawa, M., "Fast Interlaminar Fracture of a Compressively Loaded Composite Containing a Defect," Fifth DOD/NASA Conference on Fibrous Composites in Structural Design, New Orleans, Louisiana, January 27-29, 1981 .

6. Cha1, M., Babcock, C. D., and Knauss, W. G., " On the Failure of Laminated Plates by Delamination Buckling," Report No. 80-16, California Institute of Technology, July 1980.

7. Chatterjee, S. N., and Pipes, R. B., "Study of Graphite/Epoxy Composites for Material Flow Criticality," MSC TFR 1106/1103, Nov. 1980, Contract \#N62269-79-C-0209, Naval Air Development Center.

8. Almroth, B. 0., Brogan, F. A., and Stanley, G. M., "Structural Analysis of General She11s," Vol. II, User Instructions for STAGSC-1, Lockheed Palo Alto Research Laboratory, Palo Alto, CA 94304, December 1982. (Available as NASA CR-165671, 1981.)

9. Ashton, J. E., and Whitney, J. M., "Theory of Laminated Plates," Progress In Materials Sclence Series, Vol. IV, Technomic, Conn., 1970.

10. Dym, C. L., and Shames, I. H., "Solid Mechanics - A Variational Approach," McGraw Hi11, New York, 1973.

11. Bert, C. W. and Francis, P. H., "Composite Material Mechanics: Structural Mechanics," AIAA J., Vol. 12, No. 9, 1974.

12. Tsai, S. W., and Hahu, H. T., "Introduction to Composite Materials," Technomic, Conn., 1980.

13. Ramkumar, R. L., "Fatigue Degradation in Compressively Loaded Composite Laminates," NASA CR 165681, April 1981. 
Table 1.- Material Elastic Properties

\begin{tabular}{|c|c|c|c|c|}
\hline \multirow{2}{*}{ Material } & \multicolumn{3}{|c|}{ Modulus, GPa (MSI) } & \multirow{2}{*}{$\begin{array}{c}\text { Polsson ratio } \\
v_{\text {lt }}\end{array}$} \\
\hline & $\mathrm{E}_{\ell}$ & $E_{t}$ & $G_{\text {lt }}$ & \\
\hline Aluminum & $\begin{array}{r}68.95 \\
(10.0)\end{array}$ & $\begin{array}{r}68.95 \\
(10.0)\end{array}$ & $\begin{array}{l}26.32 \\
(3.82)\end{array}$ & 0.31 \\
\hline Graphite/epoxy & $\begin{array}{l}131.0 \\
(19.0)\end{array}$ & $\begin{array}{l}13.0 \\
(1.89)\end{array}$ & $\begin{array}{l}6.4 \\
(0.93)\end{array}$ & 0.34 \\
\hline
\end{tabular}




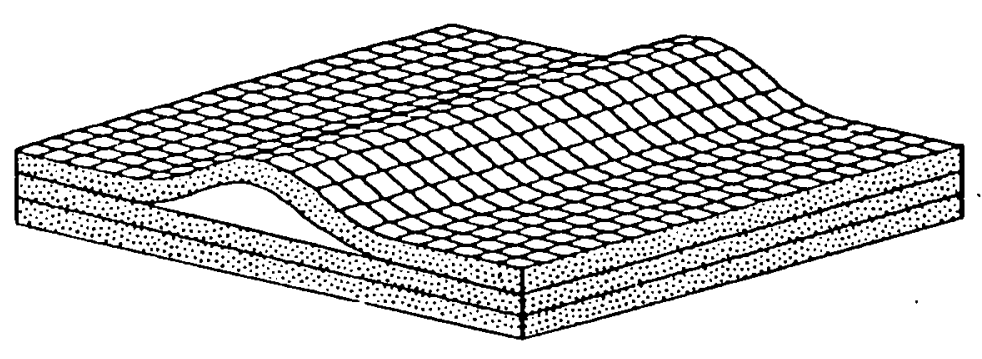

STRIP

ธั

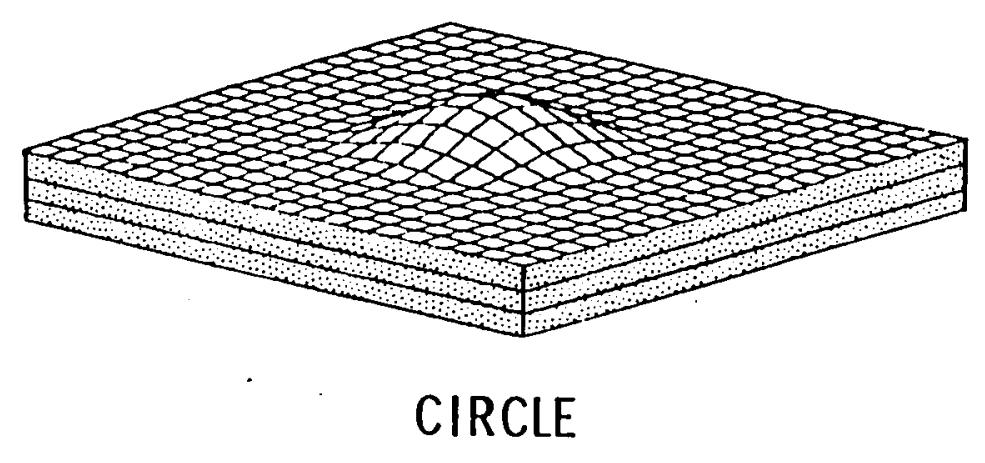

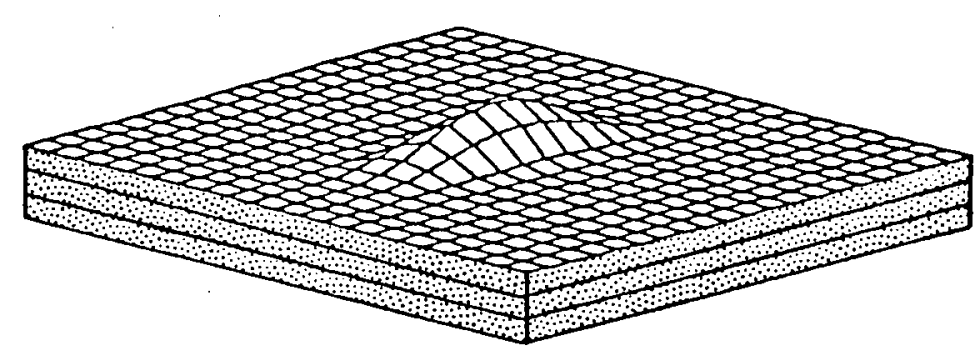

RECTANGLE

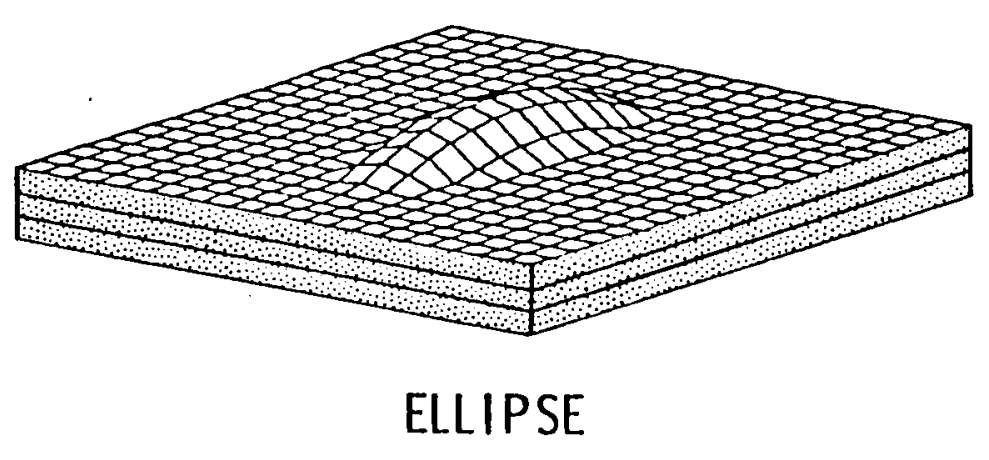

$\cdot$

Figure 1.- Shapes of delaminations. 


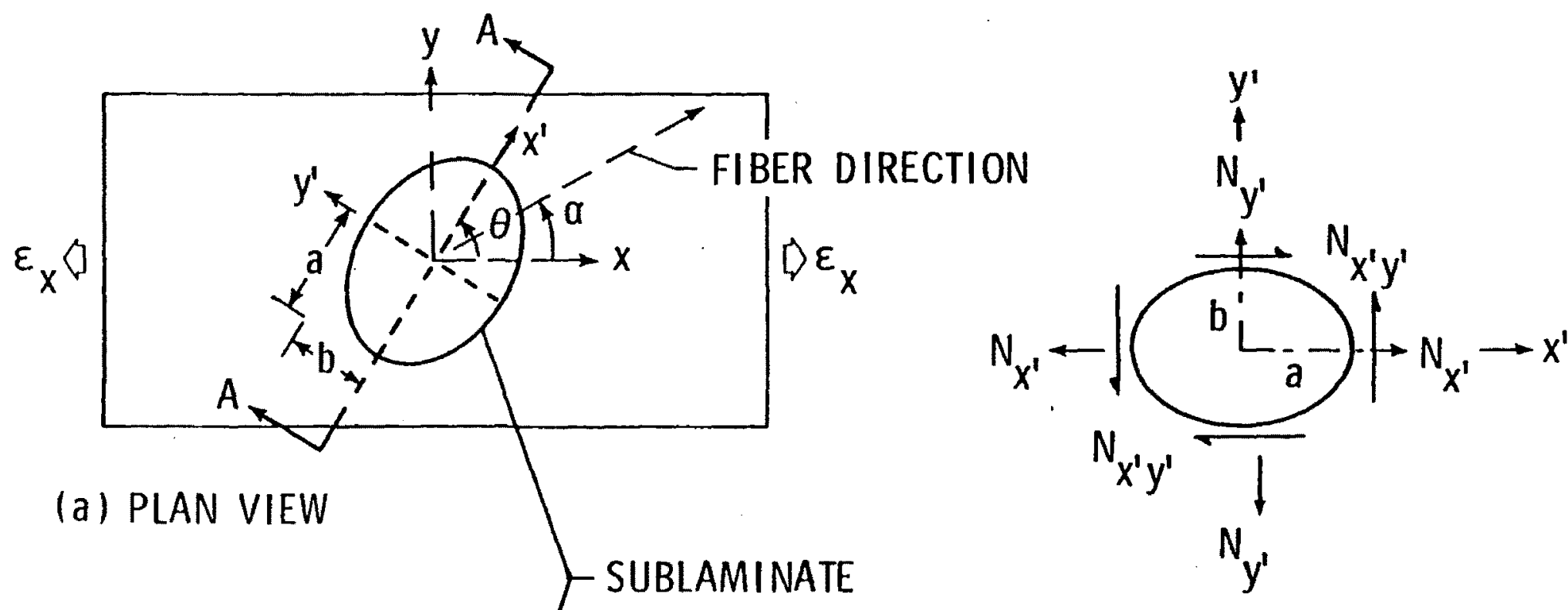

(c) FREE BODY DIAGRAM OF THE SUBLAMINATE

(b) SECTION A-A -BASE LAMINATE
(QUASI-ISOTROPIC) 


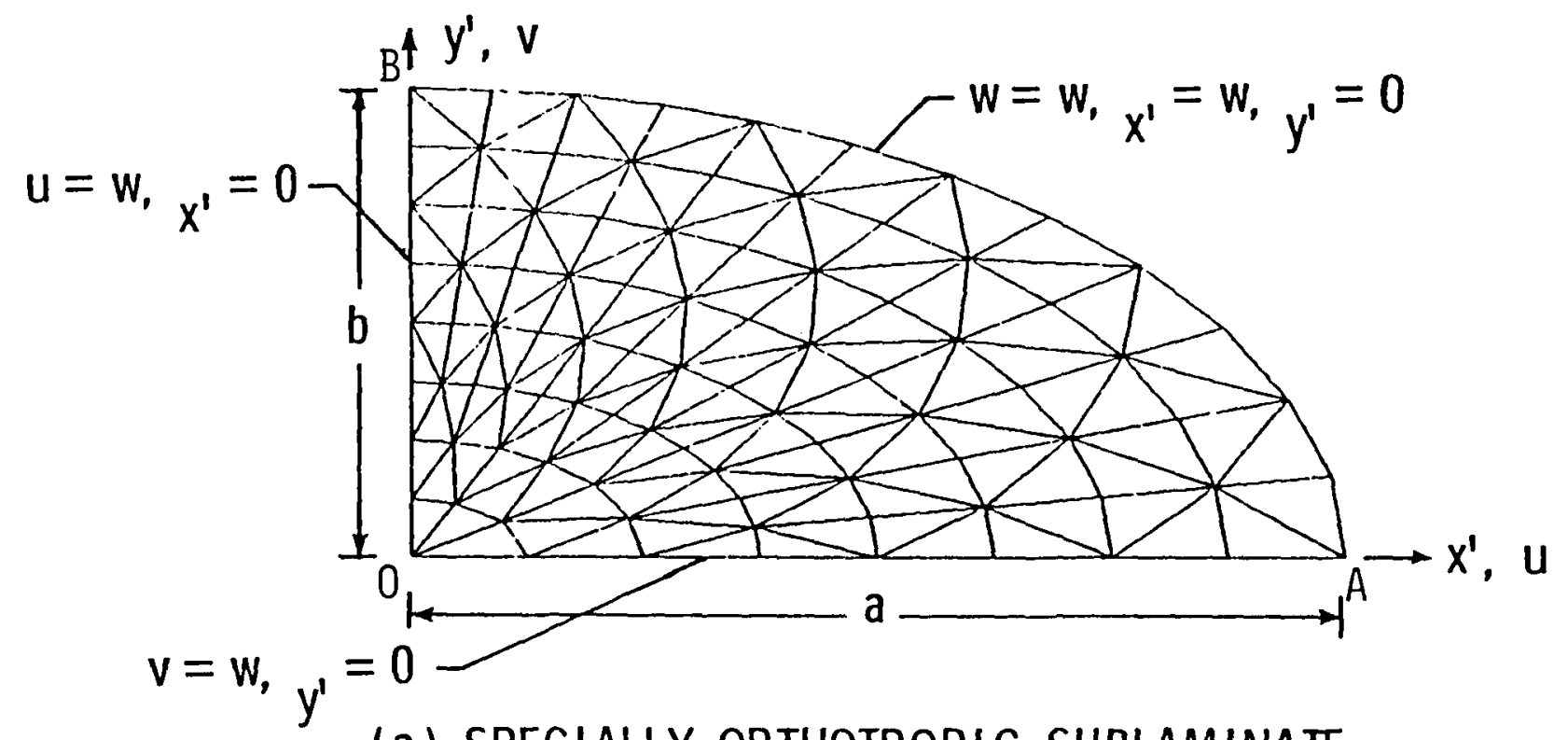

(a) SPECIALLY ORTHOTROPIC SUBLAMINATE

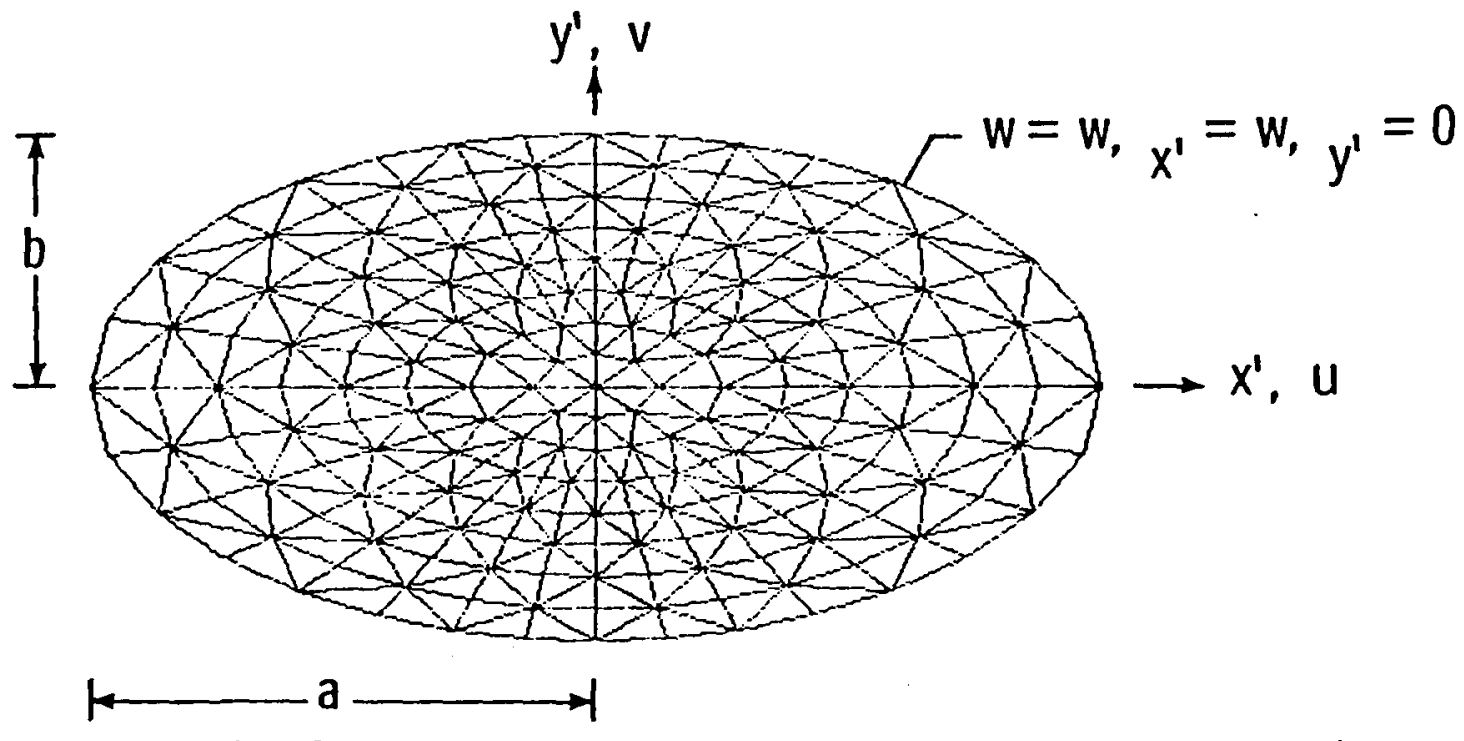

(b) ANISOTROPIC SUBLAMINATE

Figure 3.- Finite-element idealizations. 


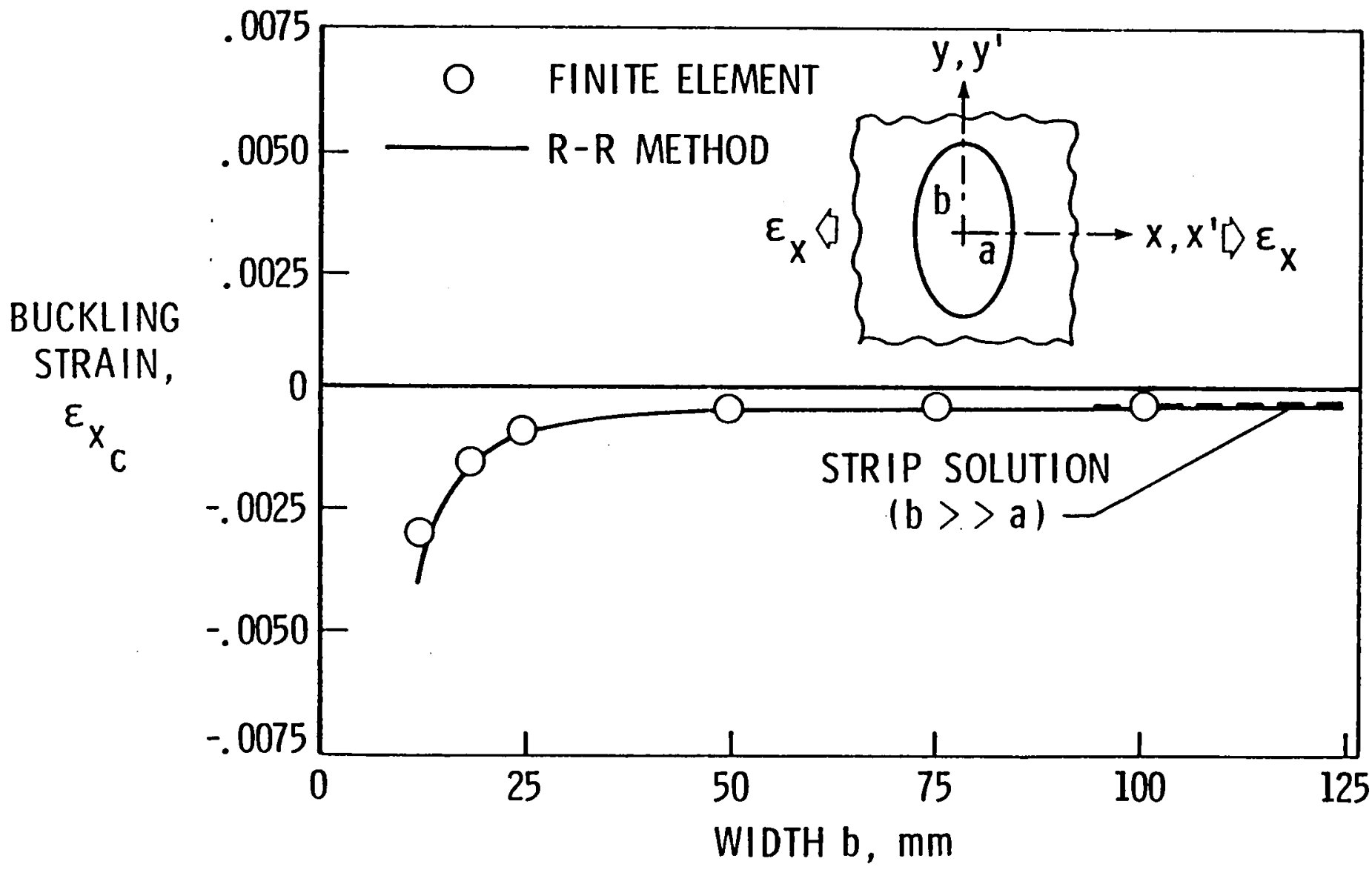

Figure 4.- Aluminum sublaminate: effect of sublaminate width on buckling strain. $(\mathrm{a}=25.4 \mathrm{~mm}, \mathrm{~h}=0.51 \mathrm{~mm})$ 


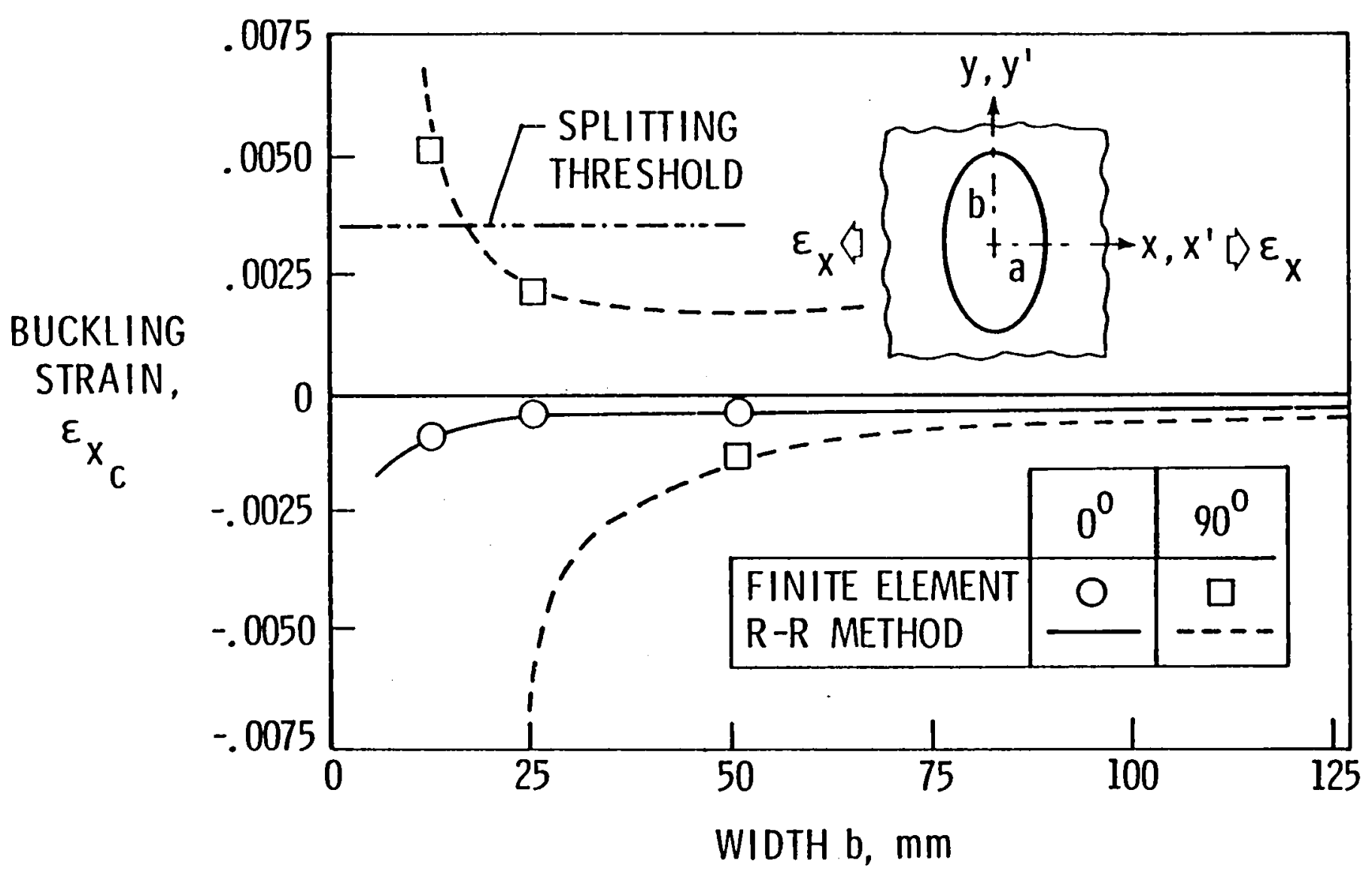

Figure 5.- Specially orthotropic sublaminate: effect of sublaminate width (b) on buckling strain. $(a=25.4 \mathrm{~mm}, \mathrm{~h}=0.51 \mathrm{~mm}$, graphite/epoxy $)$ 


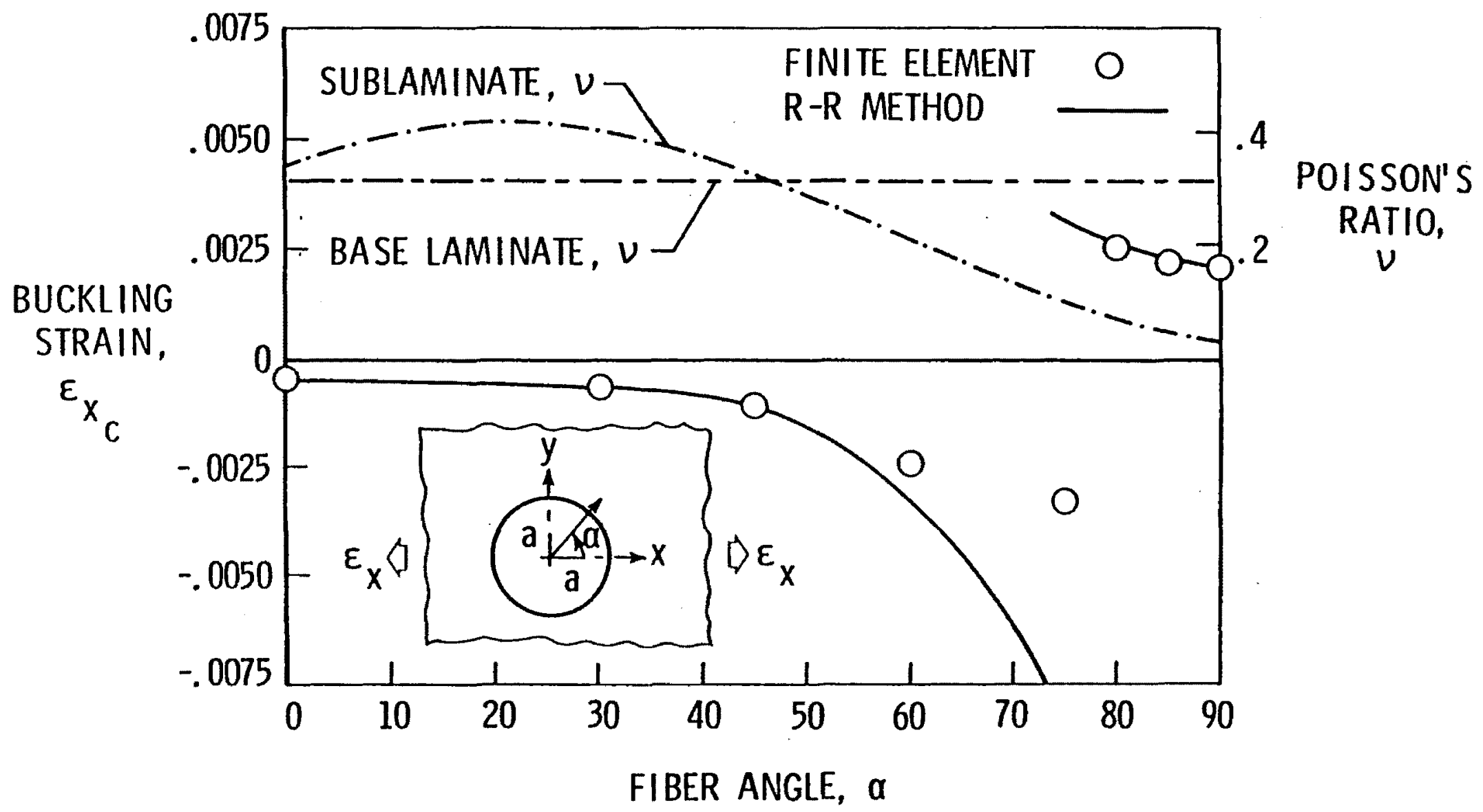

Figure 6.- Circular sublaminate: effect of fiber angle on buckling strain. ( $a=25.4 \mathrm{~mm}, \mathrm{~h}=0.51 \mathrm{~mm}$, graphite/epoxy) 


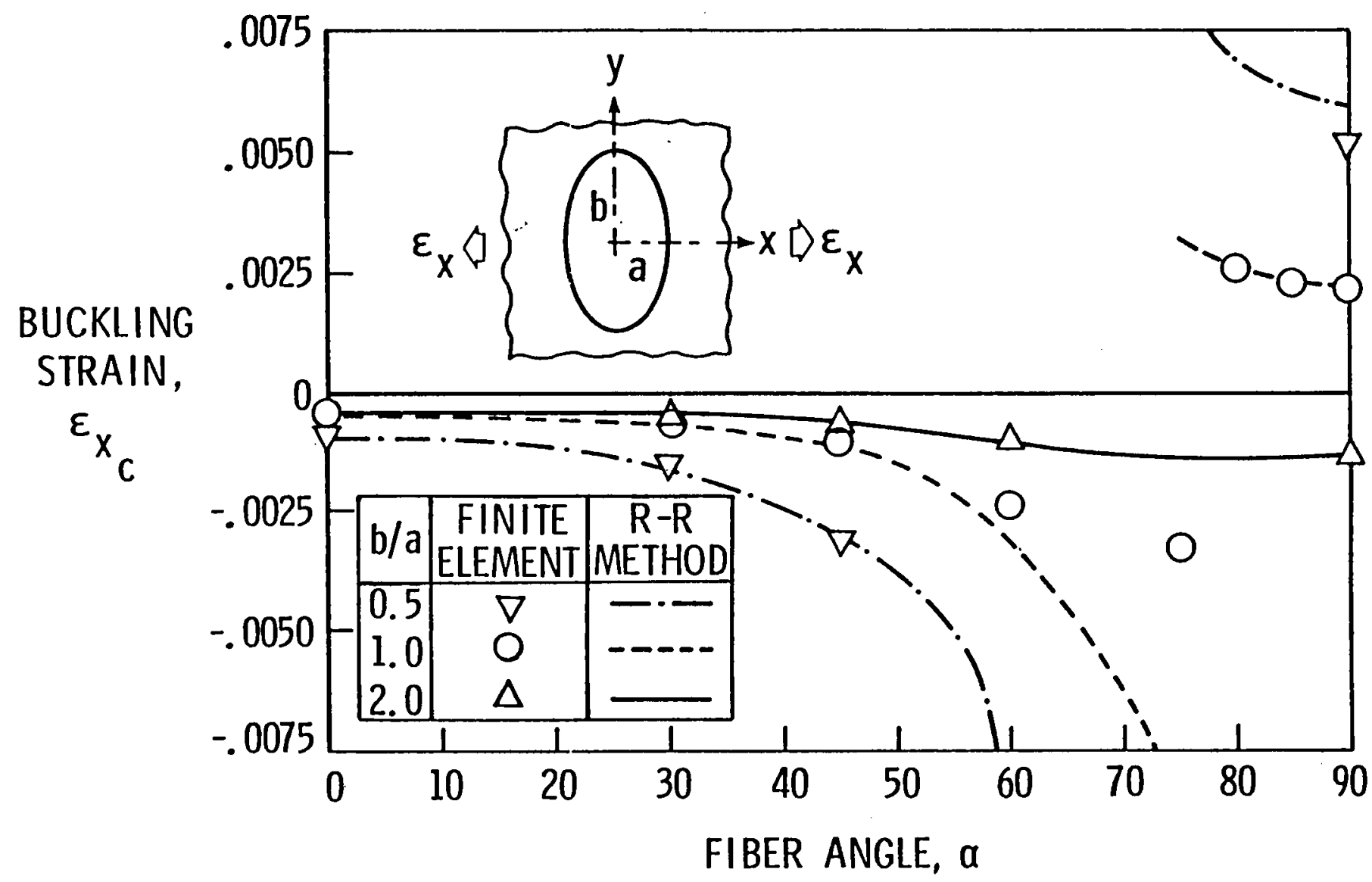

Figure 7.- Elliptical sublaminate: effect of fiber angle on buckling strain. ( $a=25.4 \mathrm{~mm}, \mathrm{~h}=0.51 \mathrm{~mm}$, graphite/epoxy) 


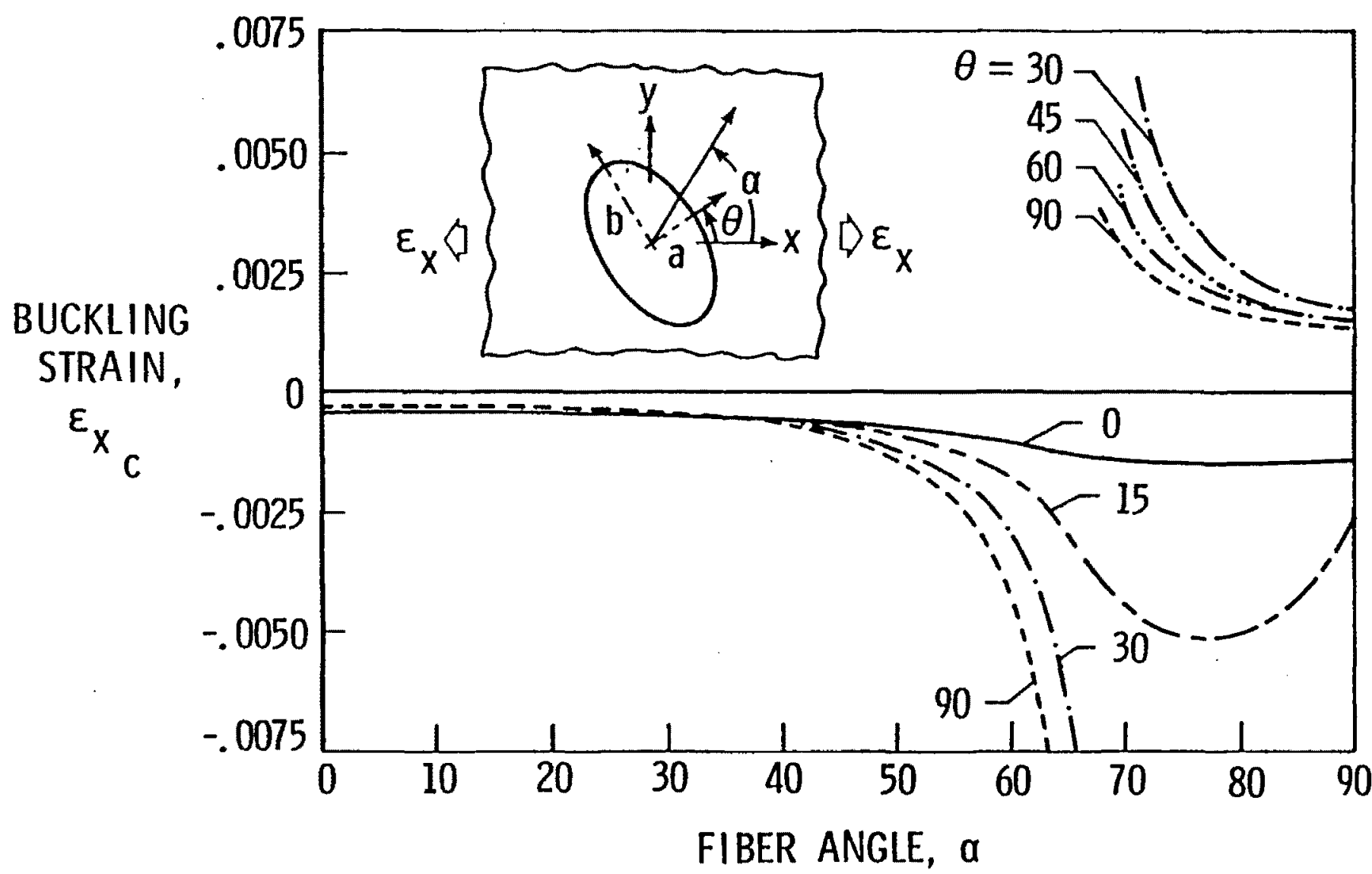

Figure 8.- Unidirectional oblique sublaminate: effect of fiber angle and sublaminate angle $(\theta)$ on buckling strain. $(a=25.4 \mathrm{~mm}, b=50.8 \mathrm{~mm}, \mathrm{~h}=0.51 \mathrm{~mm}$, graphite/epoxy) 


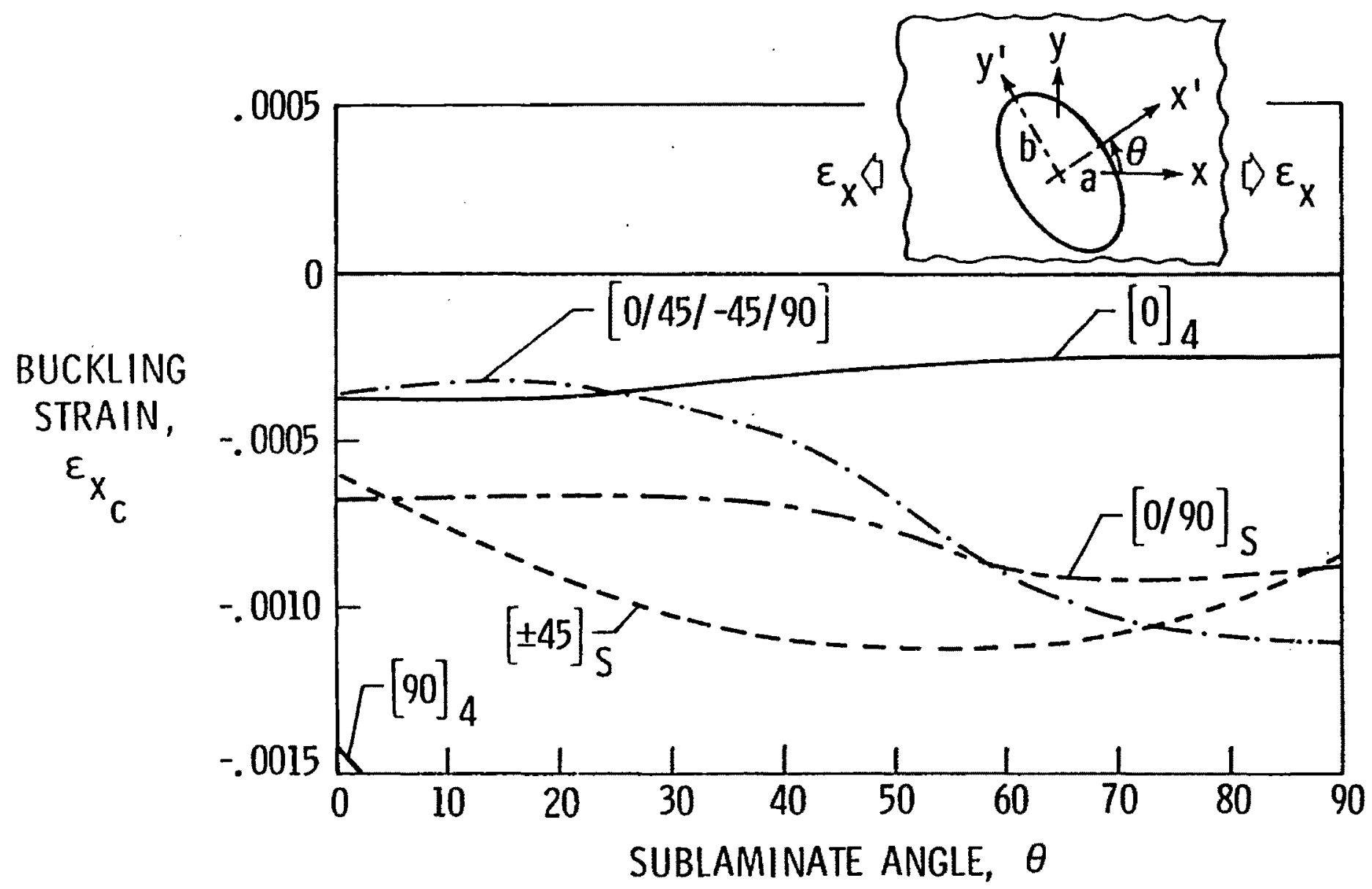

Figure 9.- Oblique sublaminates: effect of sublaminate angle on buckling strain. ( $\mathrm{a}=25.4 \mathrm{~mm}, \mathrm{~b}=50.8 \mathrm{~mm}, \mathrm{~h}=0.51 \mathrm{~mm}$, graphite/epoxy) 


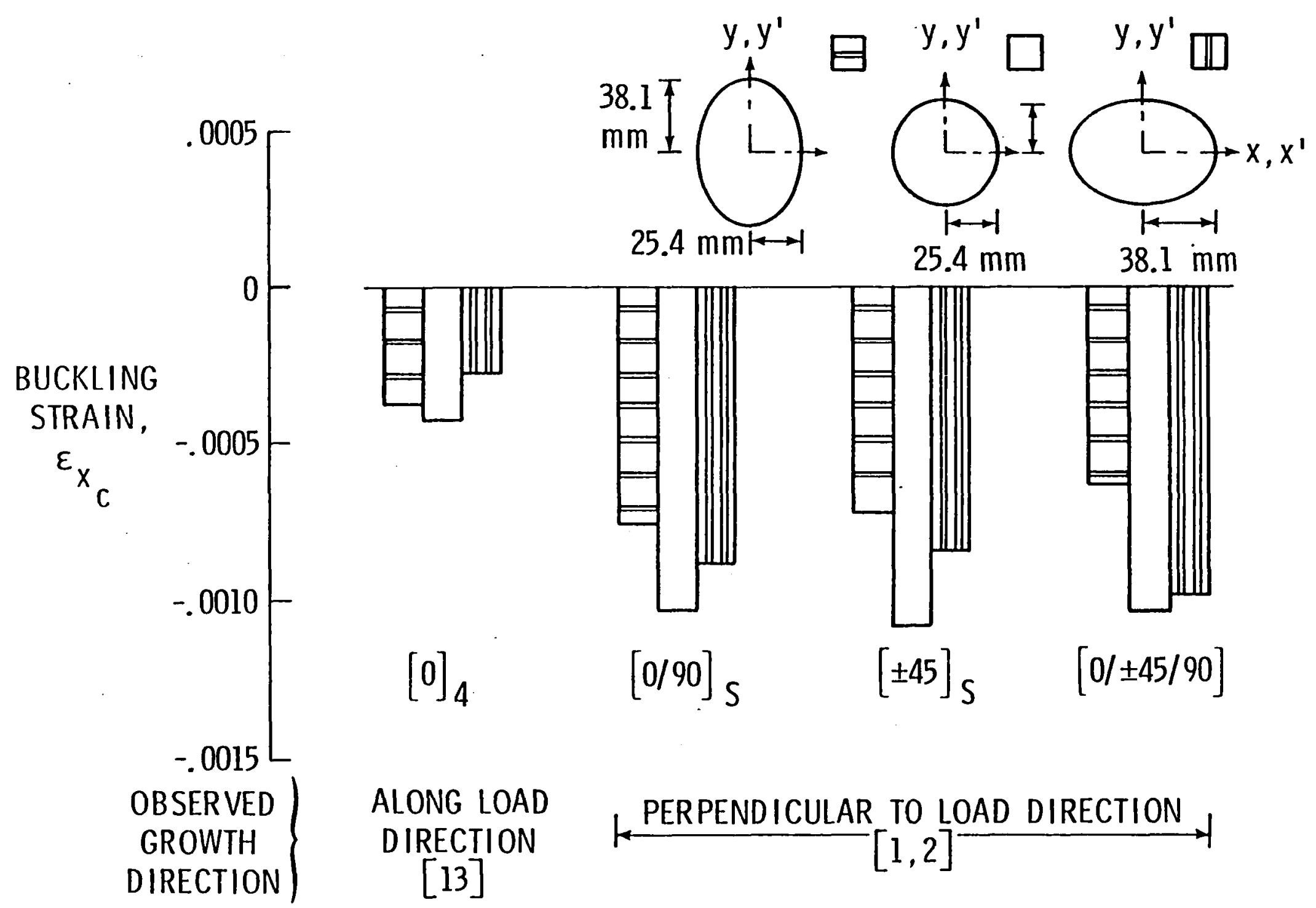

Figure 10.- Buckling strains for three sublaminate configurations.

( $h=0.51 \mathrm{~mm}$, graphite/epoxy) 


\begin{tabular}{|c|c|}
\hline $\begin{array}{l}\text { 1. Report No. } \\
\text { NASA TM-85755 }\end{array}$ & 3. Recipient's Catalog No. \\
\hline \multirow{2}{*}{$\begin{array}{l}\text { 4. Title and Subtitle } \\
\text { BUCKLING OF A SUBLAMINATE IN A QUASI-ISOTROPIC } \\
\text { COMPOSITE LAMINATE }\end{array}$} & $\begin{array}{l}\text { 5. Report Date } \\
\text { February } 1984\end{array}$ \\
\hline & $\begin{array}{l}\text { 6. Performing Organization Code } \\
534-06-23-03\end{array}$ \\
\hline $\begin{array}{l}\text { 7. Author(s) } \\
\text { K. N. Shivakumar and J. D. Whitcomb }\end{array}$ & 8. Performing Organization Report No. \\
\hline \multirow{2}{*}{$\begin{array}{l}\text { 9. Performing Organization Name and Address } \\
\text { NASA Langley Research Center } \\
\text { Hampton, VA } 23665\end{array}$} & 10. Work Unit No. \\
\hline & 11. Contract or Grant No. \\
\hline \multirow{2}{*}{$\begin{array}{l}\text { 12. Sponsoring Agency Name and Address } \\
\text { Nationa1 Aeronautics and Space Administration } \\
\text { Washington, DC } 20546\end{array}$} & $\begin{array}{l}\text { 13. Type of Report and Period Covered } \\
\text { Technical Memorandum }\end{array}$ \\
\hline & 14. Sponsoring Agency Code \\
\hline
\end{tabular}

15. Supplementary Notes

16. Abstract

Buckling of a delaminated region can cause high interlaminar stresses which, in turn, lead to delamination growth. Hence, buckling strain is an important parameter in assessing the potential for strength loss due to the delamination. The objective of this study was to predict the buckling of an elliptic delamination embedded near the surface of a thick quasi-isotropic laminate. The thickness of the delaminated ply group (the sublaminate) was assumed to be small compared to the total laminate thickness. Finite-element and Rayleigh-Ritz methods were used for the analyses. The Rayleigh-Ritz method was found to be simple, inexpensive, and accurate, except for highly anisotropic delaminated regions. Effects of delamination shape and orientation, material anisotropy, and layup on buckling strains were examined. Results showed that (1) the stress state around the delaminated region is biaxial, which may lead to buckling when the laminate is loaded in tension, (2) buckling strains for multi-directional fiber sublaminates generally are bounded by those for the 0 deg and 90 deg unidirectional sublaminates, and (3) the direction of elongation of the sublaminate that has the lowest buckling strain correlates with the delamination growth direction.

17. Key Words (Suggested by Author(s))

Buckling

Finite-element

Local buckling Raleigh-Ritz

Composite laminates Sublaminates

Delamination

Compression
18. Distribution Statement

Unclassified - Unlimited

Subject Category 24

19. Security Classif. (of this report)

Unclassified
20. Security Classif. (of this page)

Unclassified

\begin{tabular}{|l|c|}
$\begin{array}{l}\text { 21. No. of Pages } \\
30\end{array}$ & $\begin{array}{c}\text { 22. Price* } \\
\mathrm{A} 03\end{array}$
\end{tabular}

*For sale by the National Technical Information Service, Springfield, Virginia 22161 
1

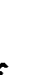

